\title{
Segregation and Precipitation at Cell Boundaries in Rapidly Solidified Austenitic Stainless Steels.
}

Zachary Hasenbusch ${ }^{1}$, Dallin Barton ${ }^{1}$, Mitchell Roze ${ }^{1}$, Andy Deal ${ }^{2}$, Ben Brown ${ }^{2}$, Davis Wilson ${ }^{3}$, Laurentiu Nastac ${ }^{1}$ and Luke Brewer ${ }^{4}$

${ }^{1}$ The University of Alabama, United States, ${ }^{2}$ Honeywell FM\&T, United States, ${ }^{3}$ Honeywell FM\&T, Overland Park, Kansas, United States, ${ }^{4}$ University of Alabama, Tuscaloosa, Alabama, United States

This presentation will discuss the observation of segregation and nanoscale precipitates along solidification cell boundaries during rapid solidification of stainless steels. Fusion-based additive manufacturing (AM) processes such as laser welding and laser powder bed fusion (LPBF) typically experience cooling rates between $10^{4} \mathrm{C} / \mathrm{s}$ and $10^{6 \circ} \mathrm{C} / \mathrm{s} .{ }^{(1)}$ Splat quenching is a more fundamental rapid solidification experiment which can be used to examine cellular solidification at these and even higher cooling rates, up to $10^{8} \mathrm{C} / \mathrm{s}$. In addition, splat quenching can be used to consider the rapid solidification on a much wider array of candidate materials for AM than LPBF as it does not require the production of a powder. At these rapid cooling rates for stainless steel, both processing techniques tend to produce cellular solidification. The size of these cells, typically $200-600 \mathrm{~nm}$, is important because this information can be used to estimate the cooling rates experienced during rapid solidification. Recent work has shown the presence of $\mathrm{Cr}$ segregation and oxide precipitation at the cell boundaries for samples produced by laser powder bed AM. ${ }^{(2)}$ In this paper, we will directly compare the cell boundary chemistries for samples produced by splat quenching (SQ) and laser powder bed fusion experiments, using the same 316L feedstock material.

There are some differences and some similarities between the LPBF and SQ microstructures apparent in STEM HAADF imaging and x-ray microanalysis. For the LPBF samples, comprised of 316L stainless steel, the STEM images show clear chromium segregation to the cell boundaries (Figure 1A). The same analysis of splat quenched samples (Figure 1B) shows little perceptible chromium segregation. It should be noted that the average cell spacing measured (350-400nm) by SEM was comparable between the two processing techniques. Both processes, LPBF and SQ, showed a consistent formation of small (typically 20-50 $\mathrm{nm}$ in diameter) oxide particles along the cell boundaries (Figure $1 \mathrm{~A}-\mathrm{B}$ ). These oxides are predominantly spherical in shape. The oxides have been observed along what are presumably cell boundaries both in primary austenite forming and primary ferrite forming alloys formed by SQ experiments. Our goal is to use the presence of the nano precipitates to identify cell boundaries in splat quenched material and use x-ray microanalysis to make estimations of the partition coefficients at these high solidification rates. The segregation of $\mathrm{Cr}, \mathrm{Ni}$, and $\mathrm{Mo}$ are quite clear in the LPBF-produced samples (Figure 2A). The Cr segregation is the most pronounced of the three elements. Segregation at the cell boundaries in the samples produced by SQ is also evident from X-ray line profiles, but it is less pronounced (Figure 2B). Potential reasons for the similarities and differences in these microstructures will be discussed.

This work was funded by the Department of Energy's Kansas City National Security Campus which is operated and managed by Honeywell Federal Manufacturing Technologies, LLC under contract number DE-NA0002839. 


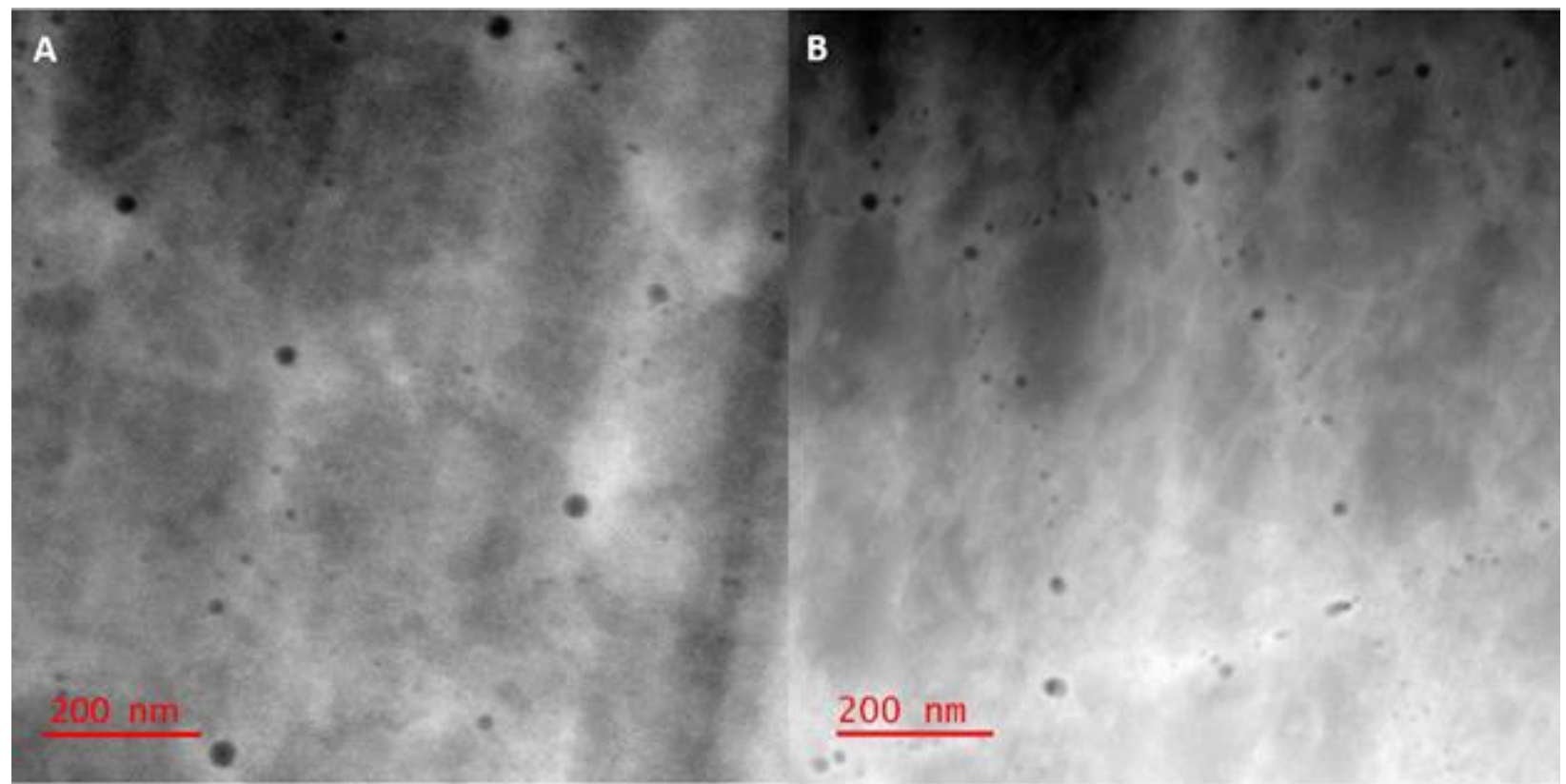

Figure 1. FIGURE 1: A.) STEM HAADF of LPBF sample and B.) STEM HAADF of splat quenched 316LSS.
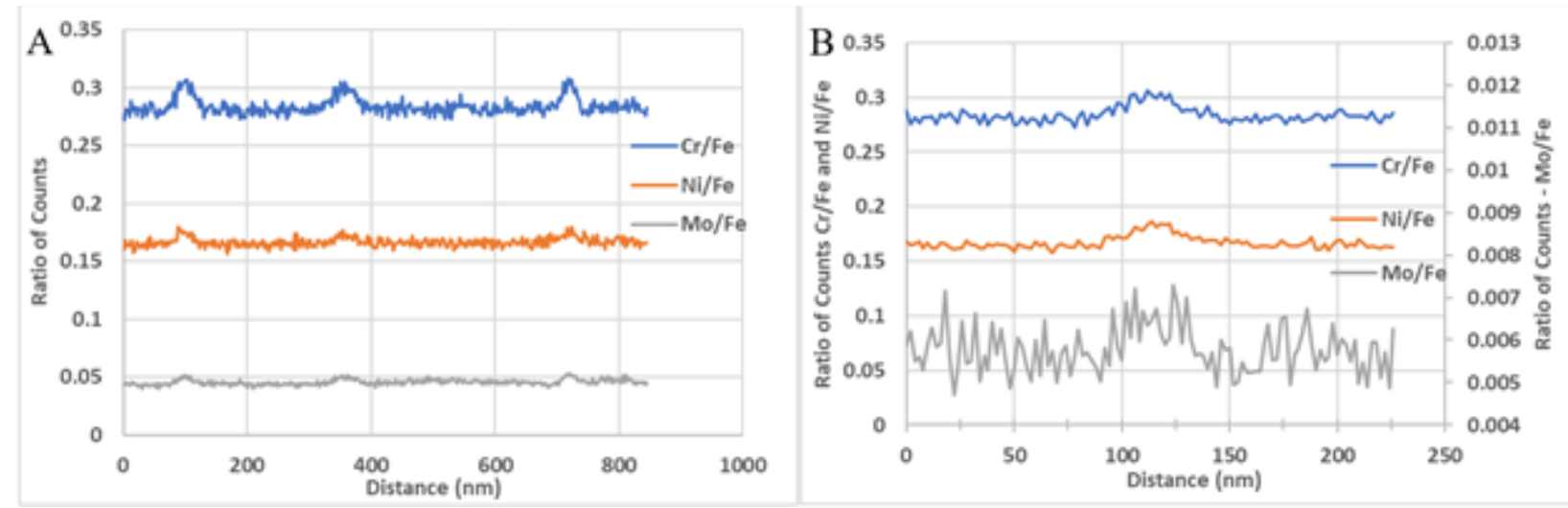

Figure 2. FIGURE 2: X-ray spectroscopy line scans across cell boundaries in A.) LPBF and B.) SQ 316LSS.

\section{References}

1.) S. Katayama, A. Matsunawa, Solidification microstructure of laser welded stainless steels, International Congress on Applications of Lasers \& Electro-Optics, Vol. 44, pg 60-67, 1984, doi:10.2351/1.5057623.

2.)) Thomas Voisin, Jean-Baptiste Forien, Aurelien Perron, Sylvie Aubry, Nicolas Bertin, Amit Samanta, Alexander Baker, Y. Morris Wang, New insights on cellular structures strengthening mechanisms and thermal stability of an austenitic stainless steel fabricated by laser powder-bed-fusion, Acta Materialia, Volume 203, 2021, 116476, ISSN 1359-6454, https://doi.org/10.1016/j.actamat.2020.11.018. 